\title{
TOPOSSEQÜÊNCIAS DE LATOSSOLOS ORIGINADOS DE ROCHAS BASÁLTICAS NO PARANÁ. II - RELAÇÃO ENTRE MINERALOGIA DA FRAÇÃO ARGILA E PROPRIEDADES FÍSICAS DOS SOLOS ${ }^{(1)}$
}

\author{
André Ademir Ghidin ${ }^{(2)}$, Vander de Freitas Melo ${ }^{(3)}$, Valmiqui Costa \\ Lima $^{(3)} \&$ Jane Maria Jonasson Costa Lima ${ }^{(3)}$
}

\begin{abstract}
RESUMO
A estrutura do solo (tipo, tamanho e grau de desenvolvimento) define a porosidade total do solo e a distribuição relativa entre macro e microporos, sendo considerada uma das mais importantes propriedades do solo do ponto de vista agrícola. O objetivo deste estudo foi avaliar a influência da mineralogia da fração argila, incluindo as características cristalográficas dos minerais, sobre as propriedades físicas de duas classes de Latossolos provenientes de rochas basálticas, em diferentes posições no relevo (toposseqüência) no Estado do Paraná. Para tal, procedeu-se à descrição morfológica dos perfis, e as amostras dos horizontes Bw1 e Bw2 foram submetidas a análises físicas e micromorfológicas. A hematita $(\mathrm{Hm})$, goethita (Gt) e Gibbsita (Gb) foram responsáveis pelo aumento na macroporosidade, porosidade total (PT) e pela redução na densidade do solo (Ds) para o Latossolo Bruno ácrico (LBw). Verificou-se influência oposta para a caulinita $(\mathrm{Ct})$. As correlações entre os atributos físicos e os teores de $\mathrm{Ct}, \mathrm{Hm}$, Gt e $\mathrm{Gb}$ na fração argila não foram significativas para o Latossolo Vermelho distroférrico (LVdf). Aparentemente, os óxidos de $\mathrm{Fe}$ e $\mathrm{Al}$ de baixa cristalinidade foram mais importantes no incremento da macroporosidade e $\mathrm{PT}$ dos horizontes do $\mathrm{LVdf}$. Com relação às características cristalográficas dos minerais da fração argila, para o LVdf, apenas os coeficientes de correlação entre o tamanho médio do cristal da Gb [DMC(110)] e a PT (correlação negativa) e a Ds (correlação positiva) foram significativos. Verificouse comportamento semelhante para o diâmetro médio do cristal da $\mathrm{Hm}$ no domínio (104) para o LBw.
\end{abstract}

Termos de indexação: estrutura do solo, porosidade do solo, micromorfologia, caulinita, óxidos de Fe e Al.

\footnotetext{
(1) Parte da Tese da Tese de Mestrado do primeiro autor. Recebido para publicação em julho de 2004 e aprovado em março de 2006.

(2) Professor do Curso Gestão Ambiental, Faculdade Palas Atena - FPA. CEP 85560-000 Chopinzinho (PR). E-mail: ghidin@chnet.com.br

(3) Professor do Departamento de Solos, Universidade Federal do Paraná - UFPR. Rua dos Funcionários 1540, Departamento de Solos, Juvevê, CEP 80035-050 Curitiba (PR). E-mails: vanderfm@ufpr.br; valmiqui@ufpr.br
} 


\title{
SUMMARY: OXISOL TOPOSEQUENCES DEVELOPED FROM BASALTIC ROCKS IN PARANÁ STATE, BRAZIL. II - RELATIONSHIP BETWEEN CLAY FRACTION MINERALOGY AND PHYSICAL SOIL PROPERTIES
}

\begin{abstract}
Soil structure (type, size and development) defines the total soil porosity and macro and microporosity distribution, and is considered to be one of the most important agricultural soil properties. The aim of this work was to study the effect of the clay fraction mineralogy, including the crystallographic mineral characteristics, in the soil physical properties of two Oxisols developed from the basaltic rocks, in different landscape positions (toposequence) in Paraná State, Brazil. With this objective, the soil profile was morphologically described and the Bw1 and Bw2 horizons samples were submitted to physical and micromorphological characterizations. The hematite $(\mathrm{Hm})$, goethite $(\mathrm{Gt})$ and gibbsite $(\mathrm{Gb})$ were responsible for the increased macroporosity and total porosity (TP) and reduced bulk density (BD) in the Red-Yellow Latosol (LBw). The effect of kaolinite (Ka) was opposite. The correlation between physical properties and $\mathrm{Ka}, \mathrm{Hm}, \mathrm{Gt}$, Gb concentration in the clay fraction were not significant for the Dusky Red Latosol ( LVdf). The amorphous Fe and Al oxides apparently were more important for the increased macroporosity and improved TP of the LVdf horizons. The only significant correlation in crystallographic characteristics of the clay fraction minerals was observed between Gb crystal size [MCD(110)] and TP (negative correlation) and BD (positive correlation) for the LVdf. A similar behavior was observed for mean crystal diameter of $\mathrm{Hm}$ (104 direction) for the $\mathrm{LBw}$.
\end{abstract}

Index terms: soil structure, soil porosity, micromorphology, kaolinite, Fe and Al oxides.

\section{INTRODUÇÃO}

A caulinita (Ct), gibbsita $(\mathrm{Gb})$, goethita $(\mathrm{Gt}) \mathrm{e}$ hematita $(\mathrm{Hm})$ são os principais minerais da fração argila dos Latossolos brasileiros, apresentando diferentes concentrações e características físicoquímicas (Curi \& Franzmeier, 1984; Singh \& Gilkes, 1992a,b; Melo et al., 2001a,b). A participação quantitativa desses minerais nas características físicas dos solos foi discutida por alguns autores (Resende, 1985; Schwertmann \& Kampf, 1985; Resende et al., 1992; Pinheiro-Dick \& Schwertmann, 1995; Ferreira et al., 1999a,b; Giarola et al., 2002; Pedrotti et al., 2003). Contudo, não foi explorada, nesses trabalhos, a influência das características cristalográficas dos minerais da fração argila sobre a formação de agregados e definição da porosidade desta classe de solo.

Avaliando apenas o efeito da espécie mineral da fração argila sobre as propriedades físicas dos solos, Deshpande et al. (1968) reportaram a maior participação dos óxidos de Al na estabilidade dos agregados em relação aos óxidos de Fe. Já o trabalho de Pinheiro-Dick \& Schwertmann (1995) não conseguiu distinguir o efeito destas duas classes de minerais, em que a presença dos óxidos de $\mathrm{Fe}$ e $\mathrm{Al}$ resultou indistintamente na alta estabilidade dos agregados dos Oxissolos. Segundo os autores, tanto as formas de Fe pobremente cristalinas quanto a $\mathrm{Gt}$ e Hm participaram efetivamente dos processos de agregação destes solos.

Schwertmann \& Kämpf (1985), estudando as propriedades da Gt e Hm em solos cauliníticos da
Região Central e Sul do Brasil, mostraram que esses minerais se agregam mutuamente, em vez de recobrirem as partículas da $\mathrm{Ct}$, não concordando com a opinião amplamente difundida de que o revestimento da Ct pelos óxidos de Fe é a principal causa para a forte agregação dos solos de clima tropical e subtropical.

Resende (1985), Resende et al. (1992) e Resende et al. (1997) atribuíram, principalmente, à Hm, Gt e Gb o efeito de desorganizador de minerais filossilicatos na fração argila, destacando-se a Ct. Assim, o maior teor desses constituintes corresponderá a um maior grau de desorganização em nível microscópico e, conseqüentemente, a uma estrutura mais próxima do tipo granular. Por outro lado, esses autores discutiram também o efeito da Ct na estrutura dos Latossolos, atribuindo ao arranjo face a face do mineral a estrutura predominantemente em blocos.

Neste sentido, Ferreira et al. (1999a) observaram em Latossolos do Sudeste do Brasil que a Ct e Gb são os constituintes mineralógicos que exercem maior influência sobre as propriedades físicas, sendo responsáveis pelo desenvolvimento da estrutura dos solos. Tais autores, baseados nos trabalhos realizados por Emerson (1959) e Resende (1985), apresentaram as seguintes conclusões sobre a estruturação dos Latossolos brasileiros, dividindoos em cauliníticos e gibbsíticos: (a) o Latossolo caulinítico, pela avaliação micromorfológica, revelou que a distribuição dos grãos de quartzo, em relação ao plasma, é eminentemente porfirogrânica, isto é, os grãos estão envoltos num plasma denso, contínuo, 
com pouca tendência ao desenvolvimento de microestrutura. Esse fenômeno acarreta o surgimento de estruturas em blocos, fazendo com que os solos apresentem-se mais compactos, menos permeáveis, com menor estabilidade de agregados em água e maior tendência à erosão laminar. Desta forma, os autores justificam a menor estabilidade de agregados do solo desenvolvidos sob clima temperado; (b) nos Latossolos gibbsíticos, utilizando a mesma técnica, observou-se que a distribuição dos grãos de quartzo em relação ao plasma segue o padrão "agglutinic", ou seja, apresenta desenvolvimento de microestrutura com predomínio de poros de empacotamento composto. Isto envolve o surgimento de estrutura do tipo granular, apresentando-se mais porosos, mais permeáveis, com maior estabilidade de agregados em água e menores valores de densidade do solo (Ferreira et al., 1999b).

O objetivo deste estudo foi avaliar a influência da mineralogia da fração argila, incluindo as características cristalográficas dos minerais, sobre as propriedades físicas de duas classes de Latossolos provenientes de rochas basálticas, em diferentes posições no relevo (toposseqüência) no estado do Paraná.

\section{MATERIAL E MÉTODOS}

\section{Descrição geral das áreas e amostragem dos solos}

As áreas estudadas pertencem aos Municípios de Guarapuava e Cascavel (PR), localizadas no Terceiro Planalto Paranaense, fazendo parte do Planalto de Guarapuava, situados entre os Rios Iguaçu e Piquiri, limitando-se a oeste pelo rio Paraná e a leste pela serra da Boa Esperança (Maack, 1968). De maneira geral, o Terceiro Planalto é a região fisiográfica paranaense mais simples pelas suas formas e estruturas, com relevo levemente ondulado e chapadas de encostas suaves (Bigarella et al., 1994).

Segundo Schneider (1970), em área próxima a Cascavel, a rocha é o basalto vacuolar, o qual apresenta coloração preta, brilho resinoso, com predomínio de plagioclásio, piroxênios, magnetita e presença de alguns secundários (cloritas esverdeadas e óxidos e hidróxidos de Fe). Já em Guarapuava, foi identificado o andesi-basalto pórfiro (rocha mais ácida), o qual apresenta coloração cinzaclara a cinza-escura, com predomínio de plagioclásio (andesina), piroxênio (hiperstênio e augita), opacos (magnetita) e quartzo.

Com objetivo de analisar a influência dos minerais da fração argila nas propriedades físicas dos solos sob condições naturais, a toposseqüência no Município de Guarapuava localizou-se no Parque
Ambiental das Araucárias, situado na latitude $25^{\circ} 21^{\prime} 50$ " Sul e longitude $51^{\circ} 28^{\prime} 33^{\prime \prime}$ Oeste, com altitude de $1.068 \mathrm{~m}$. Da mesma forma, a toposseqüência do Município de Cascavel localizouse no Parque Ambiental de Cascavel, situado na latitude $24^{\circ} 27^{\prime} 21^{\prime \prime}$ Sul e longitude $53^{\circ} 27^{\prime} 19^{\prime \prime}$ Oeste, com altitude de $781 \mathrm{~m}$. As toposseqüências apresentaram declividade média de $5 \%$ e comprimento médio da rampa de $400 \mathrm{~m}$. Foram abertas quatro trincheiras em cada área, distribuídas uniformemente da parte mais alta até à parte mais baixa da paisagem (Quadro 1).

Os solos foram morfologicamente descritos, segundo Lemos \& Santos (1996), dando especial atenção à estrutura do horizonte Bw, determinandose o tipo, grau de desenvolvimento e tamanho dos agregados. Para caracterização e classificação dos solos, amostras coletadas em todos os horizontes dos perfis foram submetidas a análises químicas $(\mathrm{pH}$, teores trocáveis de $\mathrm{Ca}, \mathrm{Mg}, \mathrm{K}, \mathrm{Al}$, acidez potencial e C orgânico - Pavan et al., 1992) e à análise granulométrica (Embrapa, 1997). Os dados completos destas determinações e análises são apresentados por Ghidin et al. (2006). Os solos foram classificados como Latossolo Bruno ácrico húmico (LBw) (toposseqüência de Guarapuava) e Latossolo Vermelho distroférrico húmico (LVdf) (toposseqüência de Cascavel) (Embrapa, 1999).

Foram coletadas amostras deformadas e indeformadas dos horizontes Bw1 e Bw2 para análises físicas e micromorfológicas. Com auxílio de uma faca, verificou-se a consistência do solo, pela resistência oferecida à sua penetração, e foram atribuídas notas, que variaram de zero, consistência extremamente solta, até cinco, para muito coesa.

\section{Densidade do solo (Ds) e densidade real (Dr)}

A Ds foi determinada pelo método do anel volumétrico e a Dr pelo método do balão volumétrico preenchido com com álcool etílico (Embrapa, 1997).

\section{Estabilidades dos agregados via úmida}

A estabilidade de agregados foi determinada em amostra indeformada e seca ao ar e peneirada manualmente em peneiras de malha 4 e $2 \mathrm{~mm}$. Foram analisados os agregados com diâmetro entre 2 e $4 \mathrm{~mm}$, tomando-se três repetições de $25 \mathrm{~g}$. Para determinação da umidade, uma amostra da mesma classe de agregados foi levada à estufa a $105^{\circ} \mathrm{C}$ por $12 \mathrm{~h}$. As amostras foram colocadas em Placas de Petri, onde foram umedecidas lentamente com atomizador durante $15 \mathrm{~min}$, a uma distância aproximada de $40 \mathrm{~cm}$. Após o umedecimento, as amostras ficaram em repouso por duas horas, e, posteriormente, colocadas em jogo de peneiras com malha 2,$0 ; 1,0 ; 0,50 ; 0,25$ e $0,105 \mathrm{~mm}$ e agitadas em um oscilador mecânico (Yoder), durante 15 min, imersas em água. Os agregados retidos em cada 
Quadro 1. Características gerais ${ }^{(1)}$, análise granulométrica e teor de carbono orgânico (CO) dos solos

\begin{tabular}{|c|c|c|c|c|c|c|c|c|c|c|c|c|c|c|c|}
\hline \multirow{2}{*}{ Amostra } & \multirow{2}{*}{ Perfil/classe } & \multirow{2}{*}{ Hor. } & \multirow{2}{*}{ Prof. } & \multirow{2}{*}{ Situação $^{(2)}$} & \multirow{2}{*}{ Drenagem $^{(3)}$} & \multirow{2}{*}{ Estrutura $^{(4)}$} & \multirow{2}{*}{ Res..$^{(5)}$} & \multirow{2}{*}{ Cons. ${ }^{(6)}$} & \multicolumn{5}{|c|}{ Análise granulométrica( ${ }^{(7)}$} & \multirow{2}{*}{$\begin{array}{c}\text { Relação } \\
\text { silte/ } \\
\text { argila }\end{array}$} & \multirow{2}{*}{ CO } \\
\hline & & & & & & & & & A & S & $\mathbf{A F}$ & AG & $\mathbf{A T}$ & & \\
\hline & & & $\mathrm{cm}$ & & & & & & & 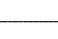 & $\mathrm{kg}^{-1}$ & & - & & $\mathrm{g} \mathrm{kg}^{-1}$ \\
\hline 1 & P1 LBw & Bw1 & $58-120$ & TSE & $\mathrm{AD}$ & $\mathrm{F}, \mathrm{MP}, \mathrm{G}$ & 2 & MF & 770 & 190 & 20 & 20 & 40 & 0,24 & 13,0 \\
\hline 2 & P1 LBw & Bw2 & $120-200$ & & & $\mathrm{M}, \mathrm{P}, \mathrm{BS}$ & 5 & $\mathrm{~F}$ & 760 & 190 & 20 & 30 & 50 & 0,25 & 3,3 \\
\hline 3 & P2 LBw & Bw1 & $50-110$ & TMSE & $\mathrm{AD}$ & $\mathrm{M}, \mathrm{MP}, \mathrm{G}$ & 2 & $\mathrm{~F}$ & 760 & 190 & 20 & 30 & 50 & 0,25 & 13,6 \\
\hline 4 & P2 LBw & $\mathrm{Bw} 2$ & $110-200$ & & & $\mathrm{M}, \mathrm{MP}, \mathrm{BS}$ & 5 & FI & 770 & 150 & 40 & 40 & 80 & 0,19 & 5,1 \\
\hline 5 & P3 LBw & Bw1 & $54-110$ & TME & $\mathrm{AD}$ & $\mathrm{F}, \mathrm{P}, \mathrm{G} / \mathrm{BS}$ & 3 & MF & 780 & 180 & 20 & 20 & 40 & 0,23 & 13,6 \\
\hline 6 & P3 LBw & Bw2 & $110-200$ & & & $\mathrm{M}, \mathrm{MP}, \mathrm{BS}$ & 4 & $\mathrm{~F}$ & 760 & 200 & 10 & 30 & 40 & 0,26 & 4,5 \\
\hline 7 & P4 LBw & Bw1 & $107-160$ & TIE & DM/DI & $\mathrm{M}, \mathrm{MP}, \mathrm{BS}$ & 4 & MF & 760 & 210 & 30 & 30 & 60 & 0,28 & 19,0 \\
\hline 8 & P4 LBw & Bw2 & $160-210$ & & & $\mathrm{M}, \mathrm{P}, \mathrm{BS}$ & 5 & FI & 680 & 260 & 40 & 20 & 60 & 0,38 & 8,8 \\
\hline 9 & P5 LVdf & Bw1 & $60-153$ & TSE & $\mathrm{AD}$ & $\mathrm{F}, \mathrm{MP}, \mathrm{G}$ & 2 & $\mathrm{~F}$ & 770 & 190 & 20 & 20 & 40 & 0,24 & 13,0 \\
\hline 10 & P5 LVdf & Bw2 & $153-210$ & & & M, MP, BS & 4 & $\mathrm{~F}$ & 760 & 190 & 30 & 20 & 50 & 0,25 & 5,1 \\
\hline 11 & P6 LVdf & Bw1 & $65-142$ & TMSE & $\mathrm{AD}$ & $\mathrm{F}, \mathrm{P}, \mathrm{G}$ & 2 & MF & 740 & 200 & 40 & 20 & 60 & 0,27 & 10,0 \\
\hline 12 & P6 LVdf & Bw2 & $142-177$ & & & $\mathrm{M}, \mathrm{P}, \mathrm{BS}$ & 4 & $\mathrm{~F}$ & 750 & 190 & 30 & 30 & 60 & 0,25 & 4,5 \\
\hline 13 & P7 LVdf & Bw1 & $67-145$ & TME & $\mathrm{AD}$ & $\mathrm{M}, \mathrm{MP}, \mathrm{BS}$ & 3 & $\mathrm{~F}$ & 700 & 230 & 40 & 30 & 70 & 0,32 & 10,6 \\
\hline 14 & P7 LVdf & Bw2 & $145-176$ & & & $\mathrm{M}, \mathrm{MP}, \mathrm{BS}$ & 3 & FI & 680 & 200 & 70 & 50 & 120 & 0,29 & 7,5 \\
\hline 15 & P8 LVdf & Bw1 & $58-107$ & TIE & $\mathrm{AD}$ & $\mathrm{F}, \mathrm{MP}, \mathrm{BS}$ & 3 & $\mathrm{~F}$ & 680 & 230 & 50 & 40 & 90 & 0,33 & 13,6 \\
\hline 16 & P8 LVdf & Bw2 & $107-160$ & & & $\mathrm{M}, \mathrm{P}, \mathrm{BS}$ & 5 & $\mathrm{~F}$ & 680 & 250 & 40 & 60 & 100 & 0,38 & 8,8 \\
\hline
\end{tabular}

(1) Descrição morfológica, segundo Lemos \& Santos (1996). Classificação dos solos (Embrapa, 199): LBw - Latossolo Bruno ácrico húmico, LVdf - Latossolo Vermelho distroférrico húmico. ${ }^{(2)}$ Situação - posição do perfil na paisagem: TSE, TMSE, TME, TIE - terço superior, médio/superior, médio e inferior de elevação, respectivamente. ${ }^{(3)}$ Drenagem: AD - acentuadamente drenado, DM/DI drenagem moderada/imperfeita. ${ }^{(4)}$ Estrutura: grau de desenvolvimento $(\mathrm{F}=$ forte, $\mathrm{M}=$ moderado), tamanho $(\mathrm{MP}=$ muito pequeno, $\mathrm{P}$ = pequeno), tipo $(\mathrm{G}=$ granular, $\mathrm{BS}=$ bloco subangular $) .{ }^{(5)}$ Resistência do horizonte $\mathrm{B}$ à penetração da faca, verificado em campo, variando de extremamente solto (0) até coeso (5). ${ }^{(6)}$ Consistência no estado úmido: $\mathrm{MF}=$ muito friável, $\mathrm{F}=$ friável, $\mathrm{FI} .=$ firme. ${ }^{(7)} \mathrm{A}$ $=$ argila, $\mathrm{S}=$ silte, $\mathrm{AF}=$ areia fina, $\mathrm{AG}=$ areia grossa e $\mathrm{AT}=$ areia total.

peneira foram transferidos para placas de porcelana e, após secagem em estufa a $105^{\circ} \mathrm{C}$ por $24 \mathrm{~h}$, determinaram-se o peso do material seco e a percentagem de cada classe de agregados (Embrapa, 1997). Para expressar a distribuição dos agregados, utilizou-se o índice por tamanho (diâmetro médio geométrico - DMG), calculado pela seguinte fórmula:

$$
\begin{gathered}
\mathrm{DMG}=10^{\mathrm{X}} \\
\mathrm{X}=[\mathrm{S}(\mathrm{n} \log \mathrm{d}) / \mathrm{Sn}]
\end{gathered}
$$

em que

$$
\begin{aligned}
\mathrm{n}= & \% \text { dos agregados retidos em determinada } \\
& \text { peneira. } \\
\mathrm{d}= & \text { diâmetro médio de determinada faixa de } \\
& \text { tamanho do agregado }(\mathrm{mm}) .
\end{aligned}
$$

\section{Porosidade do solo}

As amostras indeformadas coletadas em anel volumétrico foram saturadas com água e colocadas sob mesa de tensão, sendo retirada a água dos macroporos (poros com diâmetro $\geq 0,05 \mathrm{~mm}$ ), aplicando-se uma tensão de $60 \mathrm{~cm}$ de coluna de água. Após a retirada parcial da água, as amostras foram pesadas e levadas para secagem em estufa $105^{\circ} \mathrm{C}$ por $12 \mathrm{~h}$, determinando-se o volume de poros na amostra, conforme descrito abaixo (Embrapa, 1997):
- Porosidade total (Pt)

Pt $(\%)=100(\mathrm{Dr}-\mathrm{Ds}) / \mathrm{Dr}$;

Dr $=$ densidade real $\left(\mathrm{g} \mathrm{cm}^{-3}\right)$;

Ds $=$ densidade do solo $\left(\mathrm{g} \mathrm{cm}^{-3}\right)$.

- Microporosidade $(\%)=(a-b) / c$

$\mathrm{a}=$ peso da amostra após aplicação de uma tensão de $60 \mathrm{~cm}$ de coluna de água $(\mathrm{g})$;

$\mathrm{b}=$ peso da amostra seca a $105^{\circ} \mathrm{C}(\mathrm{g})$;

$\mathrm{c}=$ volume do cilindro $\left(\mathrm{cm}^{3}\right)$.

- Macroporosidade $(\%)=$ porosidade total microporosidade

\section{Argila dispersa em água (ADA) e grau de floculação (GF)}

A ADA e o GF foram determinados de acordo com o método proposto pela Embrapa (1997).

\section{Análise micromorfológica}

Após secagem ao ar das amostras indeformadas dos horizontes Bw1 e Bw2, procedeu-se à primeira aplicação da mistura impregnadora na proporção de $100 \mathrm{~mL}$ de resina e $70 \mathrm{~mL}$ de monômero de estireno e duas gotas de catalisador. Após cada aplicação de 
mistura impregnadora, o recipiente com a amostra de solo foi levado a um dissecador e submetido a vácuo de duas a quatro horas, até que a amostra ficasse completamente imersa na mistura. Foram realizadas de quatro a cinco aplicações, após as quais a amostra foi retirada e deixada em temperatura ambiente por cerca de 30 dias para endurecimento. Cortou-se, então, do bloco de solo impregnado, uma fatia de aproximadamente $1 \mathrm{~mm}$ de espessura, tendo sido uma de suas faces polida e colada em lâmina de vidro. Essa fatia foi desbastada em máquina de desbaste, usando carburundum de várias granulometrias, até atingir a espessura de 30 micrômetros $(0,03 \mathrm{~mm})$, quando, então, foi polida e examinada. A terminologia empregada na descrição micromorfólogica das amostras consta em Curi et al. (1986).

\section{Análise estatística}

Os dados das análises químicas e mineralógicas da fração argila apresentados por Ghidin et al. (2006) e os dados das determinações físicas dos solos foram submetidos a análises estatísticas de correlação simples (Pearson), utilizando-se o programa SPSS for Windows 10.0 .

\section{RESULTADOS E DISCUSSÃO}

\section{Descrição geral dos perfis dos solos}

A forma predominante da estrutura nos Latossolos, principalmente no horizonte Bw2, foi do tipo blocos subangulares (Quadro 1). Já no horizonte Bw1, identificou-se estrutura granular nas partes mais elevadas e blocos subangulares nas partes mais baixas das toposseqüências. Desta forma, concluise que o relevo foi o fator determinante na formação da estrutura. Segundo Moniz \& Buol (1982), além do relevo, o material de origem e o clima são importantes fatores na definição do tipo, tamanho e grau de desenvolvimento das unidades estruturais.

De maneira geral, os menores valores de resistência do solo à penetração com a faca foram observados para o horizonte Bw1 (mais superficial), principalmente para aqueles com estrutura granular (Quadro 1). Este comportamento era esperado, uma vez que as estruturas com forma esferoidal conferem ao solo maior macroporosidade e porosidade total, resultando em consistência mais solta dos horizontes (Brady, 1989). Segundo Ferreira et al. (1999b), nas partes mais baixas das toposseqüências, verifica-se maior concentração de $\mathrm{Si}$, proveniente do fluxo lateral e vertical da água pela ação da drenagem, aumentando, conseqüentemente, o teor de caulinita e fazendo com que o solo desenvolva um plasma mais denso. O horizonte $\mathrm{Bw} 2$ do $\mathrm{LBw}$, nas diferentes posições da toposseqüência, apresentou consistência determinada em amostra de solo úmido (Lemos \&
Santos, 1996), um grau menor de friabilidade em relação ao horizonte Bw1 (Quadro 1), comportamento atribuído ao fluxo vertical de Si nesta toposseqüência.

A fração argila foi o principal constituinte dos horizontes Bw1 e Bw2 dos solos (Quadro 1). Embora existam pequenas diferenças nos materiais de origem (rocha do $\mathrm{LBw}$ com maior teor de $\mathrm{Si}$ ) (Schneider, 1970) e no clima (IAPAR, 2000), os dois Latossolos apresentaram textura muito argilosa, evidenciando a intensa alteração sofrida pelo material de origem.

\section{Propriedades físicas dos solos}

Verificou-se maior percentagem de macroporos no horizonte Bw1 dos Latossolos (Quadro 2), concordando com os dados da descrição morfológica (estrutura, resistência a penetração com a faca e consistência dos solos) (Quadro 1). A variação na percentagem de macroporos foi mais acentuada ao longo da toposseqüência do $\mathrm{LBw}$, com redução do topo para a base. Neste ponto da toposseqüência, o solo apresentou-se mais adensado (Quadro 1), aumentando o volume de microporos (Quadro 2). No $\mathrm{LVdf}$, o volume de microporos foi menor que no LBw, conferindo ao LVdf maior drenagem e menor potencial de retenção de água. Os valores da porosidade total (PT) apresentaram-se semelhantes nas partes mais altas das toposseqüências para ambos os solos.

Os valores encontrados para a densidade do solo (Ds) nas amostras do LBw, variaram de 0,77 a $1,27 \mathrm{~g} \mathrm{~cm}^{-3}$ (Quadro 2), sendo semelhantes aos valores publicados por Ker (1988) para a mesma classe de solo. Para o LVdf, os valores da Ds variaram de 0,81 a $0,96 \mathrm{~g} \mathrm{~cm}^{-3}$. No LBw, as amostras coletadas nas partes mais baixas da toposseqüência, onde o volume de macroporos foi menor, foram observados maiores valores de Ds, ou seja, os dados de porosidade total (Quadro 2) acompanharam, de maneira inversa, a variação da Ds. Considerando apenas os altos valores de macroporosidade (Quadro 2), esperava-se que os valores de Ds para o LVdf fossem menores. Este comportamento pode ser explicado pela maior presença de óxidos de Fe (Hm) e minerais ferrimagnéticos (maghemita/ magnetita) nas frações deste solo. Como resultado, os valores de densidade real (Dr) para o LVdf foram maiores $\left(2,81\right.$ a $\left.3,07 \mathrm{~g} \mathrm{~cm}^{-3}\right)$. Já para o $\mathrm{LBw}$, com maiores teores de minerais silicatados e menores teores de $\mathrm{Fe}$, os valores de $\mathrm{Dr}$ variaram de 2,56 a $2,85 \mathrm{~g} \mathrm{~cm}^{-3}$. A correlação entre o teor total de Fe e a Dr do solo foi significativa $\left(r=0,78^{* * *}\right)$.

O grau de floculação da fração da argila foi elevado para todos os horizontes (Quadro 2), apresentando condições de alta estabilidade dos agregados. A baixa quantidade de CO nas amostras analisadas (Quadro 1) contribuiu, provavelmente, para o alto grau de floculação. 
A estabilidade dos agregados nos Latossolos, avaliada pelo peneiramento úmido, pode ser demonstrada pelos valores de diâmetro médio geométrico (DMG) (Quadro 3). Por meio do DMG, verificou-se variação no tamanho dos agregados nos Latossolos, com valores oscilando entre 3,34 e 4,12 mm, no LBw, e entre 2,86 e 3,80 mm, no LVdf. Os maiores valores de DMG foram observados nos horizontes mais profundos (Quadro 3), contribuindo para a redução no volume de macroporos e porosidade total do horizonte $\mathrm{Bw} 2$, principalmente para o LBw (Quadro 2).

\section{Influência da mineralogia da fração argila nas propriedades físicas dos Latossolos}

Verificou-se que os valores de coeficiente de correlação entre as características físicas e o teor de argila dos perfis do $\mathrm{LBw}$ foram altos e significativos (Quadro 4). Horizontes mais argilosos apresentaram maior percentagem de macroporos e porosidade total. Os minerais da fração argila são importantes para manter as partículas do solo floculadas, além de dar maior estabilidade aos agregados.

Quadro 2. Características físicas das amostras dos solos ${ }^{(1)}$

\begin{tabular}{|c|c|c|c|c|c|c|c|c|c|}
\hline Amostra & Perfil/classe & Horizonte & Macro & Micro & $\mathbf{P T}$ & Dr & Ds & ADA & GF \\
\hline & & & \multicolumn{3}{|c|}{$-\%$} & \multicolumn{2}{|c|}{$\mathrm{g} \mathrm{cm}^{-3}$} & \multicolumn{2}{|c|}{ — $\%$} \\
\hline 1 & P1 LBw & Bw1 & 30 & 41 & 71 & 2,70 & 0,77 & 2 & 93 \\
\hline 2 & P1 LBw & Bw2 & 23 & 47 & 70 & 2,85 & 0,85 & 3 & 89 \\
\hline 3 & P2 LBw & Bw1 & 24 & 44 & 68 & 2,56 & 0,83 & 1 & 96 \\
\hline 4 & $\mathrm{P} 2 \mathrm{LBw}$ & Bw2 & 09 & 53 & 62 & 2,77 & 1,05 & 0 & 100 \\
\hline 5 & P3 LBw & $\mathrm{Bw} 1$ & 25 & 45 & 70 & 2,70 & 0,80 & 2 & 94 \\
\hline 6 & P3 LBw & $\mathrm{Bw} 2$ & 17 & 49 & 66 & 2,63 & 0,88 & 0 & 100 \\
\hline 7 & P4 LBw & $\mathrm{Bw} 1$ & 15 & 49 & 64 & 2,63 & 0,95 & 0 & 100 \\
\hline 8 & $\mathrm{P} 4 \mathrm{LBw}$ & Bw2 & 02 & 52 & 54 & 2,77 & 1,27 & 0 & 100 \\
\hline 9 & P5 LVdf & $\mathrm{Bw} 1$ & 30 & 41 & 71 & 2,81 & 0,81 & 0 & 100 \\
\hline 10 & P5 LVdf & $\mathrm{Bw} 2$ & 25 & 45 & 70 & 2,94 & 0,89 & 0 & 100 \\
\hline 11 & P6 LVdf & Bw1 & 24 & 43 & 67 & 2,89 & 0,96 & 0 & 100 \\
\hline 12 & P6 LVdf & $\mathrm{Bw} 2$ & 25 & 44 & 69 & 3,07 & 0,94 & 0 & 100 \\
\hline 13 & P7 LVdf & Bw1 & 31 & 41 & 72 & 2,98 & 0,84 & 0 & 99 \\
\hline 14 & P7 LVdf & $\mathrm{Bw} 2$ & 28 & 41 & 69 & 3,03 & 0,94 & 0 & 100 \\
\hline 15 & P8 LVdf & Bw1 & 29 & 41 & 70 & 2,98 & 0,86 & 0 & 100 \\
\hline 16 & P8 LVdf & $\mathrm{Bw} 2$ & 29 & 41 & 70 & 2,94 & 0,87 & 0 & 100 \\
\hline
\end{tabular}

(1) Macro = Macroporosidade, Micro = Microporosidade, $\mathrm{PT}=$ Porosidade total, Dr $=$ Densidade real, $\mathrm{Ds}=\mathrm{Densidade}$ do solo, $\mathrm{ADA}=$ Argila dispersa em água e GF = Grau de floculação.

Quadro 3. Percentagem dos agregados retidos nas diferentes classes de peneiras no ensaio de estabilidade dos agregados via úmida e diâmetro médio geométrico (DMG) das amostras dos solos

\begin{tabular}{|c|c|c|c|c|c|c|c|c|c|}
\hline \multirow{2}{*}{ Amostra } & \multirow{2}{*}{ Perfil/classe } & \multirow{2}{*}{ Horizonte } & \multicolumn{6}{|c|}{ Tamanho do agregado (mm) } & \multirow{2}{*}{ DMG } \\
\hline & & & 4 a 2 & 2 a 1 & 1 a 0,5 & 0,5 a 0,25 & 0,25 a 0,105 & $<0,105$ & \\
\hline & & & & & & $\%$ & & - & $\mathrm{mm}$ \\
\hline 1 & P1 LBw & Bw 1 & 86,52 & 4,82 & 1,12 & 0,94 & 0,61 & 5,99 & 3,36 \\
\hline 2 & P1 LBw & Bw 2 & 90,92 & 3,58 & 0,42 & 0,26 & 0,26 & 4,56 & 3,80 \\
\hline 3 & P2 LBw & Bw 1 & 85,76 & 5,36 & 1,25 & 1,21 & 0,89 & 5,53 & 3,34 \\
\hline 4 & P2 LBw & Bw 2 & 90,12 & 3,94 & 0,61 & 0,37 & 0,29 & 4,67 & 3,73 \\
\hline 5 & P3 LBw & Bw 1 & 87,49 & 3,82 & 0,89 & 0,89 & 0,68 & 6,23 & 3,37 \\
\hline 6 & P3 LBw & Bw 2 & 91,94 & 3,80 & 0,52 & 0,37 & 0,52 & 2,85 & 4,12 \\
\hline 7 & P4 LBw & Bw 1 & 89,20 & 4,32 & 0,52 & 0,44 & 0,26 & 5,26 & 3,62 \\
\hline 8 & P4 LBw & $\mathrm{Bw} 2$ & 91,72 & 3,08 & 0,42 & 0,24 & 0,22 & 4,32 & 3,87 \\
\hline 9 & P5 LVdf & Bw 1 & 83,56 & 6,42 & 1,44 & 1,48 & 1,36 & 5,74 & 3,18 \\
\hline 10 & P5 LVdf & Bw2 & 90,21 & 4,22 & 0,60 & 0,52 & 0,48 & 3,97 & 3,80 \\
\hline 11 & P6 LVdf & Bw 1 & 85,48 & 5,88 & 2,76 & 1,34 & 1,28 & 3,26 & 3,52 \\
\hline 12 & P6 LVdf & Bw2 & 88,56 & 5,48 & 0,74 & 0,56 & 0,42 & 4,24 & 3,69 \\
\hline 13 & P7 LVdf & Bw 1 & 82,21 & 7,62 & 1,66 & 1,37 & 1,18 & 5,96 & 3,12 \\
\hline 14 & P7 LVdf & Bw2 & 84,01 & 6,70 & 1,53 & 1,20 & 1,00 & 5,56 & 3,26 \\
\hline 15 & P8 LVdf & Bw 1 & 76,97 & 10,93 & 2,65 & 2,08 & 1,21 & 6,16 & 2,86 \\
\hline 16 & P8 LVdf & $\mathrm{Bw} 2$ & 82,69 & 6,45 & 1,68 & 1,50 & 1,20 & 6,48 & 3,08 \\
\hline
\end{tabular}


Quadro 4. Coeficiente de correlação simples (Pearson) entre a densidade do solo (Ds), macroporosidade (macro) e microporosidade (micro), porosidade total (PT) e diâmetro médio geométrico dos agregados (DMG) com carbono orgânico, teor de argila e características químicas e mineralógicas das amostras de argila do Latossolo Bruno (LBw) ${ }^{(1)}$

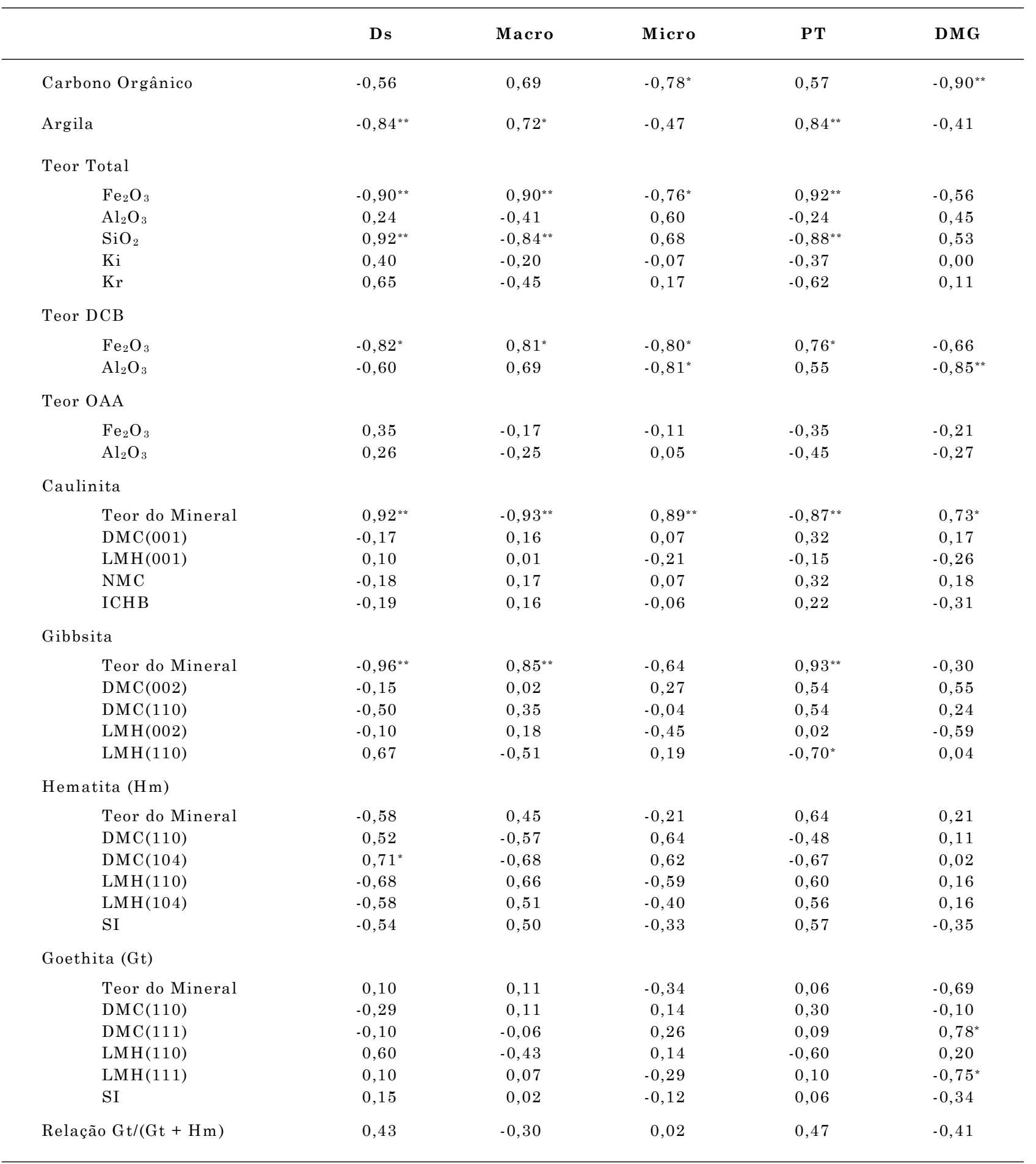

(1) Os valores para os atributos químicos e mineralógicos, os métodos empregados e os cálculos cristalográficos são apresentados no trabalho de Ghidin et al. (2006): Teores totais - digestão com água régia (mistura de $\mathrm{HCl} 36$ \%: $\mathrm{HNO}_{3} 68$ \%); Relação molar entre os teores totais de óxidos - $\mathrm{ki}=1,7 \times \mathrm{SiO}_{2} / \mathrm{Al}_{2} \mathrm{O}_{3}, \mathrm{kr}=1,7 \times \mathrm{SiO}_{2} /\left[\mathrm{Al}_{2} \mathrm{O}_{3}+\left(0,64 \times \mathrm{Fe}_{2} \mathrm{O}_{3}\right)\right]$; DCB - extração com ditionito-citratobicarbonato; OAA - extração com oxalato de amônio ácido; DMC - diâmetro médio do cristal; LMH - largura a meia altura; NMC número médio de camadas; ICHB - índice de cristalinidade de Hughes \& Brown; SI - substituição isomórfica de Fe por Al na estrutura da $\mathrm{Hm}$ e Gt.

* e ${ }^{* *}$, significativos a 0,05 e 0,01 pelo teste $\mathrm{T}$, respectivamente. 
A melhoria das condições de drenagem (aumento da macroporosidade, PT e redução na Ds) do LBw foi consistentemente acompanhada pelo aumento nos teores de óxidos de Fe total e óxidos de Fe-DCB (Quadro 4). Como resultado, observou-se redução na microporosidade ( $\mathrm{r}$ entre $\mathrm{Fe}_{2} \mathrm{O}_{3}$-total e $\mathrm{Fe}_{2} \mathrm{O}_{3}$ $\mathrm{DCB}$ e microporosidade $=-0,76^{*}$ e $-0,80^{*}$, respectivamente). O aumento nos teores de hematita $(\mathrm{Hm})$ e goethita $(\mathrm{Gt})$ favoreceram a formação de estruturas menores e com formato mais esférico (Chagas et al., 1997; Silva et al., 1998), propiciando incremento da macroporosidade e PT do solo. Na descrição morfológica dos solos, verificouse variação no tamanho, tipo e grau de desenvolvimento das estruturas (Quadro 1). Dada a ausência de correlação entre os teores de Hm e Gt e a porosidade do LBw (Quadro 4), conclui-se que a atuação os óxidos de Fe nas propriedades físicas do solo foi de forma conjunta, impossibilitando a separação dos efeitos desses constituintes. De acordo com os dados apresentados por Ghidin et al. (2006), apesar do predomínio de Gt na maioria dos horizontes do LBw, os valores para a relação Gt/ $(\mathrm{Gt}+\mathrm{Hm})$ variaram de 0,33 a 0,81 .

Adicionalmente ao efeito dos óxidos de Fe, a gibbsita (Gb) também influenciou positivamente a estruturação do LBw (r entre teores de Gb e macroporosidade, PT e Ds $=0,85^{* *}, 0,93^{* *}$ e $-0,96^{* *}$, respectivamente - Quadro 4). Segundo Resende (1985), Resende et al. (1992) e Resende et al. (1997), a Hm, Gt e Gb apresentaram efeito desorganizador dos minerais filossilicatados, notadamente a $\mathrm{Ct}$, evitando o ajuste face a face e favorecendo a formação de estruturas mais esferoidais. Neste sentido, ainda em relação ao LBw, ficou claro o efeito negativo da $\mathrm{Ct}$ na estrutura do solo, em que o aumento nos teores do mineral e nos teores de $\mathrm{SiO}_{2}$ total acarretou aumento da microporosidade e Ds e redução na macroporosidade e PT (Quadro 4). Ferreira et al. (1999a,b) também obtiveram relação direta entre Ds, desenvolvimento de plasma mais denso do solo (análise micromorfológica) e teores de Ct.

Considerando a pequena variação nos atributos físicos (Quadro 2) e nos teores dos minerais na fração argila (Ghidin et al., 2006), de maneira geral, não houve correlação entre os valores de macroporosidade, microporosidade, PT e Ds e os atributos mineralógicos considerados para o LVdf (Quadro 5). Mesmo com baixos teores na fração argila (valores oscilando entre 18 e $48 \mathrm{~g} \mathrm{~kg}^{-1}$ - Ghidin et al., 2006), os maiores valores dos coeficientes de correlação foram observados para os óxidos de $\mathrm{Fe}$ e $\mathrm{Al}$ de baixa cristalinidade (OAA), onde a presença destes minerais favoreceu a macroporosidade em detrimento da microporosidade do solo (Quadro 5). Pinheiro-Dick \& Schwertmann (1995) e Pedrotti et al. (2003) também observaram efeito positivo dos minerais de baixa cristalinidade sobre a agregação do solo. Estes minerais apresentam alta superfície específica e alta densidade de carga, o que lhes confere grande influência sobre as propriedades físico-químicas do solo.

Com relação ao diâmetro médio geométrico (DMG) dos agregados, maiores teores de carbono orgânico $(\mathrm{CO})$ levaram à redução do tamanho médio das estruturas para ambos os solos (Quadros 4 e 5). $\mathrm{O}$ menor tamanho dos agregados foi refletido na redução da microporosidade dos solos ( $\mathrm{r}$ entre $\mathrm{CO}$ e microporosidade para o $\mathrm{LBw}$ e o $\mathrm{LVdf}=-0,78^{*}$ e $-0,73^{*}$, respectivamente). Verificou-se também efeito negativo dos teores dos óxidos de Fe de baixa cristalinidade (OAA) e, ou, mais cristalinos (DCB) nos valores de DMG (Quadros 4 e 5), concordando com o efeito destes minerais sobre a porosidade dos solos (maiores valores de DMG estão associados a solos com menor volume de macroporos e de porosidade total).

Os teores dos minerais na fração argila foram mais importantes que suas características cristalográficas na definição da estrutura e porosidade dos solos (Quadros 4 e 5). Outro fator que contribuiu para este comportamento foi a reduzida variação nos valores das propriedades cristalográficas dos minerais de acordo com a profundidade do solo e posição do perfil na toposseqüência (Ghidin et al., 2006). Para o LVdf, apenas os coeficientes de correlação entre o tamanho médio do cristal da Gb [DMC(110)] e a PT (correlação negativa) e a Ds (correlação positiva) foram significativos. Verificou-se comportamento semelhante para o diâmetro médio do cristal da $\mathrm{Hm}$ no domínio (104) para o LBw. Provavelmente, as menores partículas de Gb e Hm, por apresentarem maior atividade (maior superfície específica), foram mais importantes na formação das estruturas granulares, o que resultou no aumento da PT e redução da Ds do solo. Além do efeito na forma dos agregados, a presença destes minerais favoreceu a redução do tamanho das estruturas (Silva et al., 1998).

\section{Micromorfologia}

Foram examinadas seções delgadas de horizontes selecionados (horizonte Bw1 e Bw2), dando ênfase aos seguintes aspectos: trama, plasma e poros. Estas características foram classificadas de acordo com Curi et al. (1986).

\section{Latossolo Bruno ácrico}

As amostras dos horizontes Bw1 do LBw dos perfis 1, 2 e 3 (Quadro 1 e Figura 1) apresentaram trama porfírica aberta, com poros de empacotamento composto e localmente do tipo grânica. No horizonte Bw1 do perfil 4, o plasma denso contínuo, com menor tendência ao desenvolvimento de microestrutura, contribuiu para o surgimento da trama porfírica aberta, com poros do tipo aplainados irregulares. Poros do tipo cavidades foram observados em todos os perfis. 
Quadro 5. Coeficiente de correlação simples (Pearson) entre a densidade do solo (Ds), macroporosidade (macro) e microporosidade (micro), porosidade total (PT) e diâmetro médio geométrico dos agregados (DMG) com carbono orgânico, teor de argila e características químicas e mineralógicas das amostras de argila do Latossolo Vermelho (LVdf) ${ }^{(1)}$

\begin{tabular}{|c|c|c|c|c|c|}
\hline & Ds & Macro & Micro & $\mathbf{P T}$ & DMG \\
\hline Carbono Orgânico & $-0,23$ & 0,63 & $-0,73^{*}$ & 0,30 & $-0,81^{*}$ \\
\hline Argila & 0,01 & $-0,46$ & 0,65 & $-0,10$ & 0,70 \\
\hline $\begin{array}{l}\text { Teor Total } \\
\qquad \begin{array}{l}\mathrm{Fe}_{2} \mathrm{O}_{3} \\
\mathrm{Al}_{2} \mathrm{O}_{3} \\
\mathrm{SiO}_{2} \\
\mathrm{Ki} \\
\mathrm{Kr}\end{array}\end{array}$ & $\begin{array}{r}-0,43 \\
-0,69 \\
-0,18 \\
0,02 \\
0,13\end{array}$ & $\begin{array}{l}0,46 \\
0,37 \\
0,15 \\
0,22 \\
0,02\end{array}$ & $\begin{array}{l}-0,43 \\
-0,13 \\
-0,17 \\
-0,37 \\
-0,12\end{array}$ & $\begin{array}{r}0,34 \\
0,50 \\
0,08 \\
-0,02 \\
0,08\end{array}$ & $\begin{array}{r}-0,45 \\
0,05 \\
-0,27 \\
0,50 \\
-0,18\end{array}$ \\
\hline \multicolumn{6}{|l|}{ Teor DCB } \\
\hline $\begin{array}{l}\mathrm{Fe}_{2} \mathrm{O}_{3} \\
\mathrm{Al}_{2} \mathrm{O}_{3}\end{array}$ & $\begin{array}{l}-0,41 \\
-0,53\end{array}$ & $\begin{array}{l}0,50 \\
0,68\end{array}$ & $\begin{array}{l}-0,42 \\
-0,87^{* *}\end{array}$ & $\begin{array}{l}0,42 \\
0,24\end{array}$ & $\begin{array}{l}-0,36 \\
-0,89^{* *}\end{array}$ \\
\hline \multicolumn{6}{|l|}{ Teor OAA } \\
\hline $\begin{array}{l}\mathrm{Fe}_{2} \mathrm{O}_{3} \\
\mathrm{Al}_{2} \mathrm{O}_{3}\end{array}$ & $\begin{array}{l}-0,49 \\
-0,56\end{array}$ & $\begin{array}{l}0,76^{*} \\
0,83^{* *}\end{array}$ & $\begin{array}{l}-0,81^{*} \\
-0,87^{* *}\end{array}$ & $\begin{array}{l}0,45 \\
0,50\end{array}$ & $\begin{array}{c}-0,86^{* *} \\
0,80^{*}\end{array}$ \\
\hline \multicolumn{6}{|l|}{ Caulinita } \\
\hline $\begin{array}{l}\text { Teor do Mineral } \\
\text { DMC }(001) \\
\text { LMH(001) } \\
\text { NMC } \\
\text { ICHB }\end{array}$ & $\begin{array}{r}0,17 \\
0,44 \\
-0,50 \\
0,45 \\
-0,20\end{array}$ & $\begin{array}{r}-0,14 \\
-0,51 \\
0,47 \\
-0,54 \\
0,00\end{array}$ & $\begin{array}{r}0,34 \\
0,25 \\
-0,24 \\
0,28 \\
0,10\end{array}$ & $\begin{array}{r}0,12 \\
-0,63 \\
0,57 \\
-0,64 \\
0,10\end{array}$ & $\begin{array}{r}0,20 \\
0,06 \\
-0,15 \\
0,08 \\
-0,19\end{array}$ \\
\hline \multicolumn{6}{|l|}{ Gibbsita } \\
\hline $\begin{array}{l}\text { Teor do Mineral } \\
\text { DMC(002) } \\
\text { DMC }(110) \\
\text { LMH(002) } \\
\text { LMH }(110)\end{array}$ & $\begin{array}{l}0,37 \\
0,37 \\
0,85^{* *} \\
0,41 \\
-0,69\end{array}$ & $\begin{array}{r}-0,56 \\
-0,35 \\
-0,67 \\
-0,41 \\
0,57\end{array}$ & $\begin{array}{r}0,63 \\
0,24 \\
0,30 \\
0,24 \\
-0,24\end{array}$ & $\begin{array}{l}-0,29 \\
-0,35 \\
-0,84^{* *} \\
-0,46 \\
0,73^{*}\end{array}$ & $\begin{array}{l}0,84^{* *} \\
0,18 \\
0,35 \\
0,32 \\
-0,27\end{array}$ \\
\hline \multicolumn{6}{|l|}{ Hematita } \\
\hline $\begin{array}{l}\text { Teor do Mineral } \\
\text { DMC }(110) \\
\text { DMC }(104) \\
\text { LMH(110) } \\
\text { LMH(104) } \\
\text { SI }\end{array}$ & $\begin{array}{r}-0,34 \\
0,28 \\
0,02 \\
0,43 \\
-0,36 \\
-0,72^{*}\end{array}$ & $\begin{array}{r}0,04 \\
0,12 \\
0,02 \\
-0,24 \\
0,26 \\
0,25\end{array}$ & $\begin{array}{r}0,09 \\
-0,29 \\
0,28 \\
0,17 \\
-0,37 \\
0,23\end{array}$ & $\begin{array}{r}0,08 \\
-0,10 \\
0,30 \\
-0,23 \\
0,05 \\
0,70\end{array}$ & $\begin{array}{r}-0,11 \\
-0,30 \\
0,38 \\
0,09 \\
-0,53 \\
0,07\end{array}$ \\
\hline
\end{tabular}

(1) Os valores para os atributos químicos e mineralógicos, os métodos empregados e os cálculos cristalográficos são apresentados no trabalho de Ghidin et al. (2006): Teores totais - digestão com água régia (mistura de $\mathrm{HCl} 36$ \%: $\mathrm{HNO}_{3} 68$ \%); Relação molar entre os teores totais de óxidos - $\mathrm{ki}=1,7 \times \mathrm{SiO}_{2} / \mathrm{Al}_{2} \mathrm{O}_{3}, \mathrm{kr}=1,7 \times \mathrm{SiO}_{2} /\left[\mathrm{Al}_{2} \mathrm{O}_{3}+\left(0,64 \times \mathrm{Fe}_{2} \mathrm{O}_{3}\right)\right]$; DCB - extração com ditionito-citratobicarbonato; OAA - extração com oxalato de amônio ácido; DMC - diâmetro médio do cristal; LMH - largura a meia altura; NMC número médio de camadas; ICHB - índice de cristalinidade de Hughes \& Brown; SI - substituição isomórfica de Fe por Al na estrutura da $\mathrm{Hm}$. Os dados referentes ao teor e às características cristalográficas da goethita não foram apresentados em virtude da ausência do mineral na metade das amostras do LVdf.

${ }^{*} \mathrm{e}^{* *}$, significativos a 0,05 e 0,01 pelo teste $\mathrm{T}$, respectivamente.

Os horizontes Bw2 revelaram plasma denso, com menor tendência ao desenvolvimento de microestrutura, principalmente na amostra do perfil 4, em predominância da porfírica aberta, nas amostras dos perfis 1 e 2 (Figura 1), e porfírica fechada, nos perfis 3 e 4 . Os poros das amostras dos perfis 1, 2, 3 e 4 foram planares irregulares com cavidades. Pela micromorfologia, pôde-se observar, nos horizontes Bw2, que, do topo para as partes mais baixas da toposseqüência, ocorreu diminuição da macroporosidade, concordando com os resultados da análise física (Quadros 2 e 3). Esse fato foi atribuído principalmente ao aumento no teor de $\mathrm{Ct}$ e redução no teor de Gb e óxidos de Fe nas partes mais baixas da toposseqüência, principalmente no perfil 4 (r entre macroporosidade e nos teores de $\mathrm{Ct}, \mathrm{Gb}$ e $\mathrm{Fe}_{2} \mathrm{O}_{3}-\mathrm{DCB}=-0,93^{* * *}, 0,85^{* * *}$ e $0,81^{*}$, respectivamente - Quadro 4). 

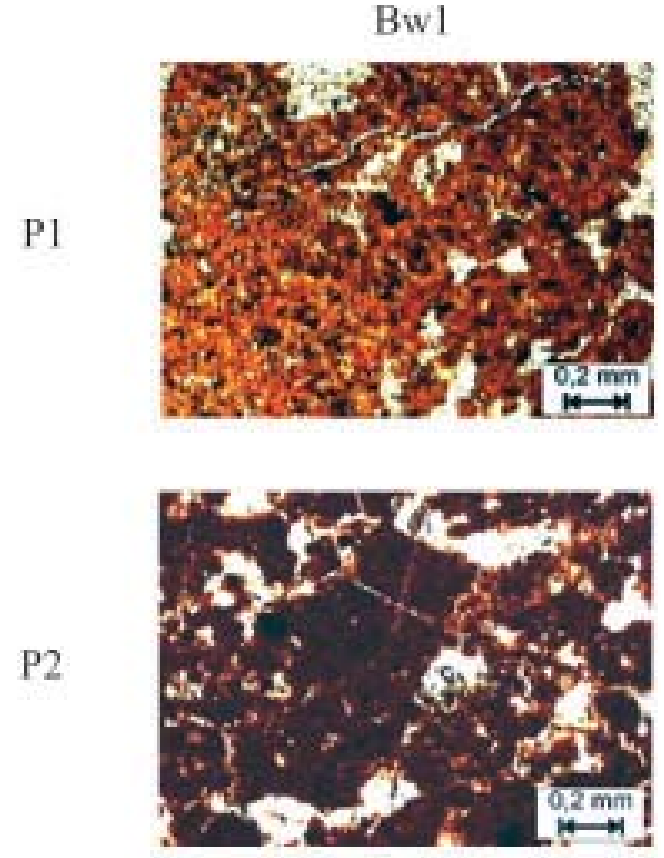

P3

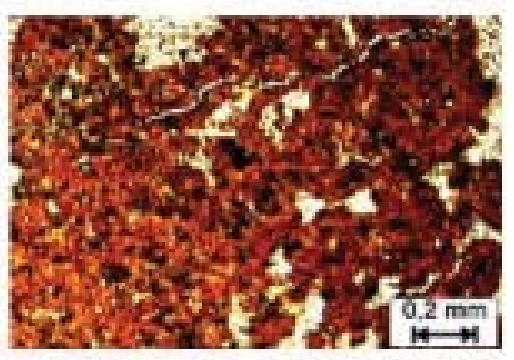

P4

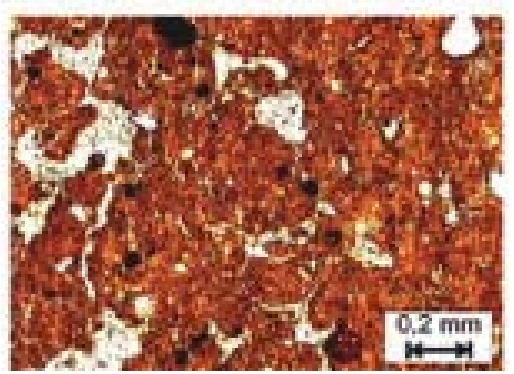

Bw2
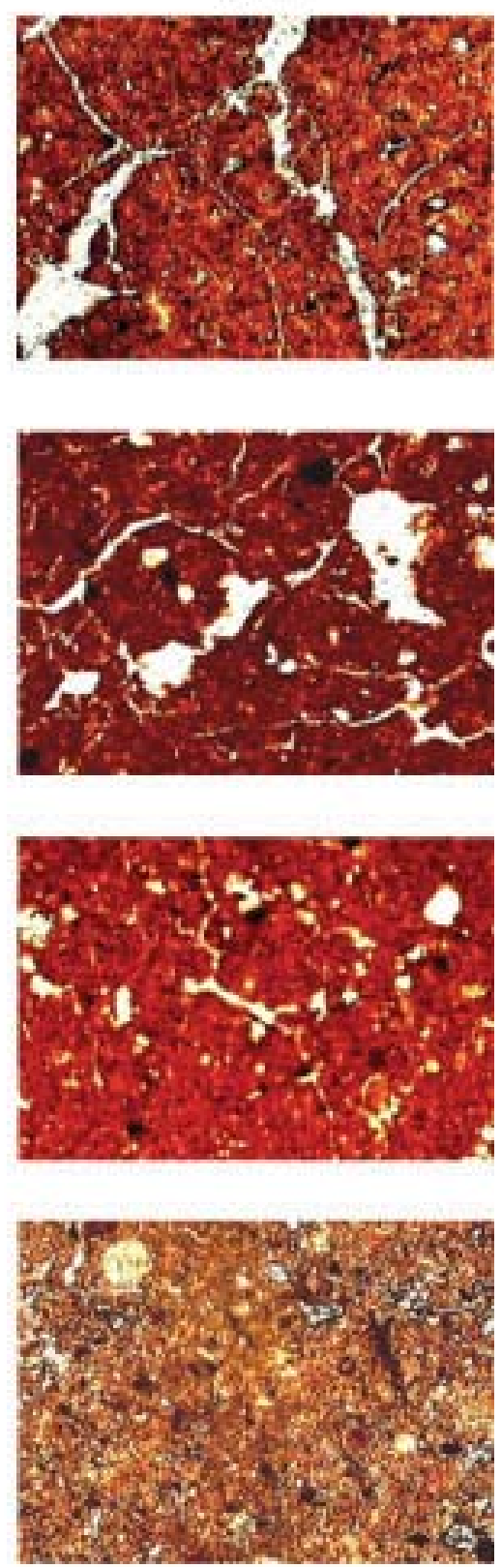

Figura 1. Microfotografia dos horizontes Bw1 e Bw2 do Latossolo Bruno ácrico húmico de diferentes perfis na toposseqüência (detalhes da posição dos perfis na paisagem - Quadro 1).

\section{Latossolo Vermelho distroférrico}

Os horizontes Bw1 do LVdf apresentaram plasma individualizado em unidades estruturais de forma arredondada e subarredondada, às vezes discretos ou coalescentes, gerando a trama grânica e granóidica, com poros de empilhamento composto, resultante do empacotamento dos agregados (Figura 2). A estrutura granular foi atribuída ao maior teor de $\mathrm{Gb}$ e óxidos de $\mathrm{Fe}$ em relação a $\mathrm{Ct}$ (Resende, 1985; Ferreira et al., 1999a). A forma granular da estrutura conferiu ao solo maior percentual de macroporosidade (Figura 2 e Quadros 1 e 2). A semelhança nas características micromorfológicas das amostras ao longo da toposseqüência (Figura 2) deveu-se à proximidade dos teores dos minerais da fração argila entre os perfis, principalmente, Ct, Gb e Hm (Ghidin et al., 2006).

Os horizontes Bw2, assim como os Bw1 desta mesma classe, apresentaram características micromorfológicas semelhantes ao longo da toposseqüência, bem como plasma também individualizado em unidades estruturais de forma 
Bw1

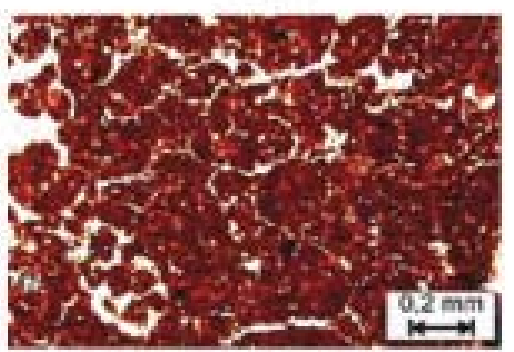

$\mathrm{P} 2$

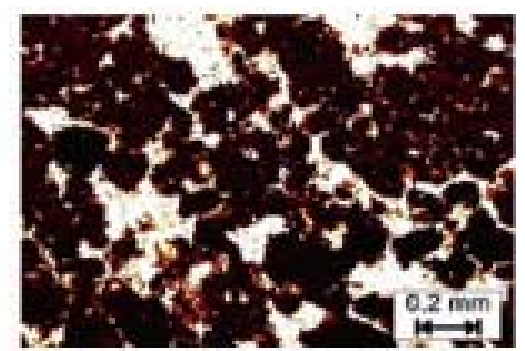

P3

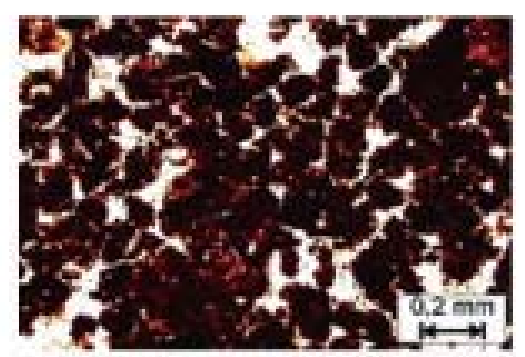

P4

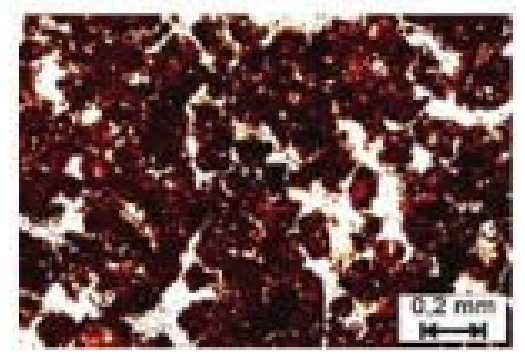

Bw2
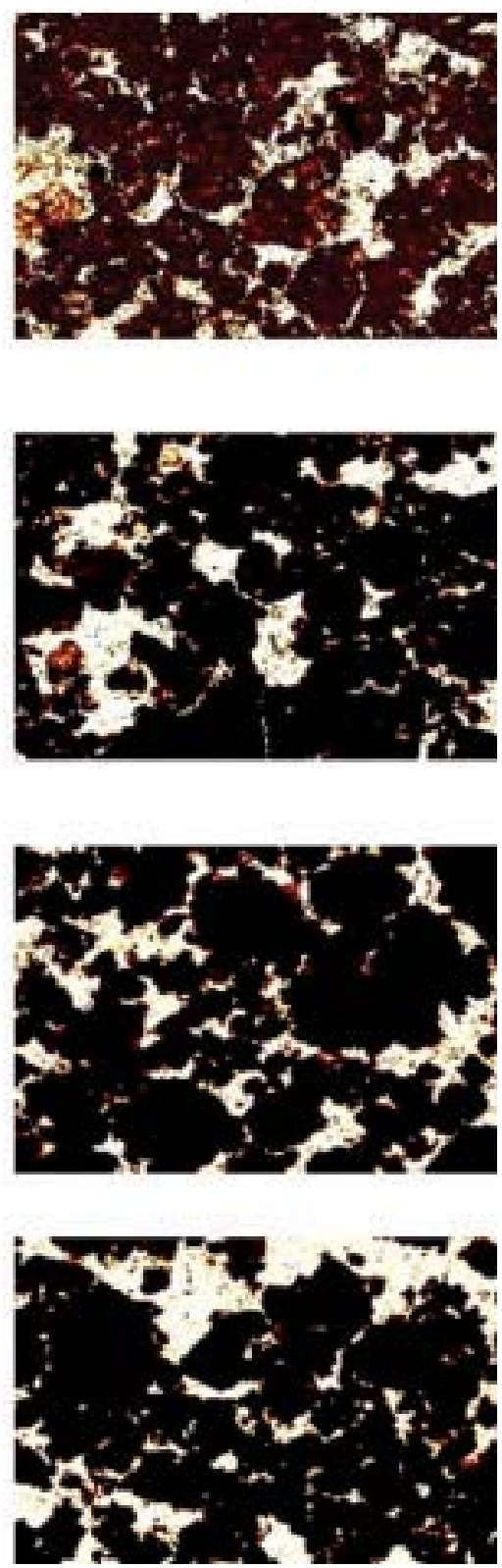

Figura 2. Microfotografia dos horizontes Bw1 e Bw2 do Latossolo Vertmelho distroférrico húmico de diferentes perfis na toposseqüência (detalhes da posição dos perfis na paisagem - Quadro 1).

arredondada e subarredondada, gerando a trama grânica e granóidica e poros de empacotamento composto.

\section{Comentário geral}

Comparando as características micromorfológicas entre os horizontes Bw1 do LVdf e LBw, percebeu-se que, mesmo sendo semelhante o teor de CO nas amostras (Quadro 1), os horizontes Bw1 do LBw apresentaram trama porfírica, portanto com menor tendência ao desenvolvimento de estrutura do tipo granular. Este comportamento foi atribuído às mudanças nas características físicas dos solos de acordo com as variações nos teores dos minerais da fração argila (Quadros 4 e 5). Nos horizontes Bw2, as diferenças micromorfológicas entre o LVdf e o LBw mostraram-se mais evidentes. O LBw apresentou estrutura em blocos, mais densa (trama porfírica), diminuindo a capacidade de drenagem nestes horizontes. Desta forma, parte do fluxo da drenagem desloca-se no sentido do topo para a base, possibilitando maior concentração de sílica nas áreas 
mais baixas da toposseqüência. Desta forma, a formação da $\mathrm{Ct}$ foi favorecida, tornando, conseqüentemente, o solo mais adensado (Quadro 4), conforme observação em campo da resistência à penetração com a faca (Quadro 1). Já as características morfológicas do LVdf, facilitaram o maior fluxo da drenagem no sentido vertical em virtude da estrutura granular (trama grânica e granóidica).

\section{CONCLUSÕES}

1. A hematita (Hm), goethita (Gt) e gibbsita (Gb) foram responsáveis pelo aumento na macroporosidade, porosidade total (PT) e redução na densidade do solo (Ds) para o Latossolo Bruno ácrico (LBw). Verificou-se influência oposta para a caulinita $(\mathrm{Ct})$, em que os maiores teores do mineral nos horizontes mais profundos e nos perfis mais baixos da toposseqüência favoreceram o desenvolvimento de estruturas maiores (maior diâmetro médio geométrico dos agregados). Como resultado, a análise micromorfológica destas amostras evidenciou a presença de plasma denso, com trama porfírica fechada.

2. As correlações entre os atributos físicos e os teores de $\mathrm{Ct}$, Hm, Gt e Gb na fração argila não foram significativas para o Latossolo Vermelho distroférrico (LVdf). Este comportamento foi atribuído à maior homogeneidade das características mineralógicas desta classe de solo ao longo da toposseqüência. Aparentemente, os óxidos de Fe e $\mathrm{Al}$ de baixa cristalinidade foram mais importantes no incremento da macroporosidade e PT dos horizontes do LVdf.

3. As características cristalográficas dos minerais da fração argila não afetaram, de forma expressiva, as características físicas do LVdf e do LBw.

\section{LITERATURA CITADA}

BIGARELLA, J.J.; BECKER, R.D. \& SANTOS, G.F. Estrutura e origem das paisagens tropicais e subtropicais. Fundamentos geológico-geográficos alteração química e física das rochas. In: BECKER, R.D., ed. Relevo cárstico e dômico. Florianópolis, Universidade Federal de Santa Catarina, 1994. p.31-76.

BRADY, N.C. Natureza e propriedade dos solos. 7.ed. Rio de Janeiro, Livraria Freitas Bastos, 1989. 878p.

CHAGAS, C.S.; CURI, N.; DUARTE, M.N.; MOTTA, P.E.F. \& LIMA, J.M. Orientação das camadas de rochas metapelíticas pobres na gênese de Latossolos sob cerrado. Pesq. Agropec. Bras., 32:539-548, 1997

CURI, N. \& FRANZMEIER, D.P. Toposequence of Oxisols from the Central Plateau of Brazil. Soil Sci. Soc. Am. J., 48:341346, 1984.
CURI, N.; LIMA, P.C. \& LEPSCH, I. Terminologia de micromorfologia de solos. In: B. Inf. SBCS, 10:9-16, 1986.

DESHPANDE, T.L., GREENLAND, P.J \& QUIRK, J.P. Changes in soil properties associated with the removal of iron and aluminium oxide. J. Soil Sci., 19:108-122, 1968.

EMERSON, W.W. The structure of soil crumbs. J. Soil Sci., 10:235-244, 1959.

EMPRESA NACIONAL DE PESQUISA AGROPECUÁRIA EMBRAPA. Manual de métodos de análise de solo. 2.ed. Rio de janeiro, Centro Nacional de Pesquisa de Solos, 1997. $212 p$.

EMPRESA BRASILEIRA DE PESQUISA AGROPECUÁRIA EMBRAPA. Centro Nacional de Pesquisas de Solos. Rio de Janeiro. Sistema Brasileiro de classificação de solos. Brasília, Serviço de Produção de Informação, 1999. 412p.

FERREIRA, M.M.; FERNANDES, B. \& CURI, N. Mineralogia da fração argila e estrutura de Latossolos da Região Sudeste do Brasil. R. Bras. Ci. Solo, 23:507-514, 1999a.

FERREIRA, M.M.; FERNANDES, B. \& CURI, N. Influência da mineralogia da fração argila nas propriedades físicas de Latossolos da Região Sudeste do Brasil. R. Bras. Ci. Solo, 23:515-524, $1999 \mathrm{~b}$.

GHIDIN, A.A.; MELO, V.F.; LIMA, V.C. \& LIMA, J.M.J.C. Toposseqüências de Latossolos originados de rochas balsáticas no Paraná. I - Mineralogia da fração argila. R. Bras. Ci. Solo, 30:293-306, 2006.

GIAROLA, N.F.B.; SILVA, A.P. \& IMHOFF, S. Relações entre propriedades físicas e características de solos na Região Sul do Brasil. R. Bras. Ci. Solo, 26:885-893, 2002.

INSTITUTO DE PESQUISA AGROPECUÁRIA DO PARANAIAPAR. Cartas climáticas do Paraná. Londrina , 2000. 1 CD ROOM.

KER, J.C. Caracterização química, física, mineralógica e micromorfológica de solos brunos subtropicais. Viçosa, Universidade Federal de Viçosa, 1988. 148p. (Tese de Mestrado)

LEMOS, R.C. \& SANTOS, R.D. Manual de descrição e coleta de solo no campo. 3.ed. Campinas, Sociedade Brasileira de Ciência do Solo, 1996. 84p.

MAACK, R. Geografia física do Estado do Paraná. Curitiba, 1968. $350 \mathrm{p}$.

MELO, V.F.; SINGH, B.; SCHAEFER, C.E.G.R.; NOVAIS, R.F. \& FONTES, M.P.F. Chemical and mineralogical properties of kaolinite-rich Brazilian soils. Soil Sci. Soc. Am. J, 65:13241333, 2001a.

MELO, V.F.; FONTES, M.P.F.; NOVAIS, R.F.; SINGH, B. \& SCHAEFER, C.E.G.R. Características dos óxidos de ferro e de alumínio de diferentes classes de solos. R. Bras. Ci. Solo, 25:19-32, 2001b.

MONIZ, A.C. \& BUOL, S.W. Formation of an Oxisol-Ultisol transition in São Paulo, Brazil: I. Double-water flow model of soil development. Soil Sci. Soc. Am. J., 46:1228-1235, 1982.

PAVAN, M.A.; BLOCH, M.F.; ZEMPUSKI, H.C.; MIYAZAWA, M. \& ZOCOLER, D.C. Manual de análise química do solo e controle de qualidade. Circular n, IAPAR, 1992. (Circular, 76) 
PEDROTTI, A.; FERREIRA, M.M.; CURI, N.; SILVA, M.L.N.; LIMA, J.M. \& CARVALHO, R. Relação entre atributos físicos, mineralogia da fração argila e formas de alumínio no solo. R. Bras. Ci. Solo, 27:1-9, 2003.

PINHEIRO-DICK, D. \& SCHWERMANN, U. Características químicas, mineralógicas e morfológicas de microagregados de oxissolos. In: CONGRESSO BRASILEIRO DE CIÊNCIA DO SOLO, 25., Viçosa, 1995. Resumos expandidos. Viçosa, Sociedade Brasileira de Ciência do Solo, 1995. p.262-264.

RESENDE, M. Aplicações de conhecimentos pedológicos à conservação de solos. Inf. Agropec., 11:3-18, 1985.

RESENDE, M.; CARVALHO FILHO, A. \& LANI, J.L Características do solo e da paisagem que influenciam a suscetibilidade à erosão. In: SIMPÓSIO SOBRE MANEJO E CONSERVAÇÃO DO SOLO NO CERRADO, Goiânia, 1990. Anais. Campinas, Fundação Cargill, 1992. p.32-67.

RESENDE, M.; CURI, N.; REZENDE, S.B. \& CORREAA, G.F. Pedologia: Base para distinção de ambientes. Viçosa, NEPUT, 1997. 367p.
SCHNEIDER, A.W. Vulcanismo basáltico da bacia do Paraná: perfil Foz do Iguaçu - Serra da Esperança. In: CONGRESSO BRASILEIRO GEOLOGIA, 26., Brasília, 1970. Anais. Brasília, Sociedade Brasileira de Geologia, 1970. p.211-217.

SCHWERTMANN, U. \& KÄMPF, N. Properties of goethite and hematite in kaolinitic soils of Southern and Central Brazil. Soil Sci., 139:344-350, 1985

SILVA, M.L.N.; BLANCANEAUX, P.; CURI, N.; LIMA, J.M.; MARQUES, J.J.G.S.M. \& CARVALHO, A.M. Estabilidade e resistência de agregados de Latossolo Vermelho-Escuro cultivado com sucessão milho-adubo verde. Pesq. Agropec. Bras., 33:97-103, 1998.

SINGH, B. \& GILKES, R.J. Properties of soil kaolinites from South-Westen Australia. J. Soil Sci., 43:645-667, 1992a.

SINGH, B. \& GILKES, R.J. Properties and distribution of iron oxides and their asociation with minor elements in the soils of South-Western Australia. J. Soil Sci., 43:77-98, 1992b. 